\title{
I 23 Functional recovery after acute myocardial infarction: a comparison between angiography, electrocardiography and cardiovascular magnetic resonance measures of microvascular injury
}

Robin Nijveldt*1, Aernout M Beek¹, Alexander Hirsch², Martin G Stoel ${ }^{3}$, Mark BM Hofman ${ }^{1}$, Victor AWM Umans ${ }^{4}$, Paul R Algra ${ }^{4}$, Jos WR Twisk ${ }^{1}$ and Albert $\mathrm{C}$ van Rossum ${ }^{1}$

Address: ${ }^{1}$ VU University Medical Center, Amsterdam, The Netherlands, ${ }^{2}$ Academic Medical Center, Amsterdam, The Netherlands, ${ }^{3}$ Medisch Spectrum Twente, Enschede, The Netherlands and ${ }^{4}$ Medical Center Alkmaar, Alkmaar, The Netherlands

* Corresponding author

from I th Annual SCMR Scientific Sessions Los Angeles, CA, USA. I-3 February 2008

Published: 22 October 2008

Journal of Cardiovascular Magnetic Resonance 2008, I0(Suppl I):A24 doi:I0.I I86/1532-429X-I0-SI-A24

This abstract is available from: http://jcmr-online.com/content/I0/SI/A24

(c) 2008 Nijveldt et al; licensee BioMed Central Ltd.

\section{Introduction}

Thrombolysis In Myocardial Infarction (TIMI) flow grade, Myocardial Blush Grade (MBG) and resolution of ST-segment elevation indirectly reflect microvascular injury. Cardiovascular magnetic resonance (CMR) allows direct visualization and quantification of microvascular obstruction (MVO) with transmural resolution.

\section{Purpose}

This study was designed to examine the relation between angiographic, electrocardiographic and CMR characteristics of microvascular injury, and its predictive value on functional recovery after acute myocardial infarction (AMI).

\section{Methods}

TIMI flow grade, MBG and ST-segment resolution were assessed in 60 patients with AMI, treated with primary stenting. CMR was performed within 9 days and at 4 months, to determine global and regional LV function, first pass perfusion defects, size and extent of late gadolinium-enhanced (LGE) infarct and MVO (Figure 1).

\section{Results}

First pass perfusion defects and LGE MVO were both related to incomplete ST resolution $(\mathrm{p}=0.002$ and $\mathrm{p}=$ 0.01 respectively), but not to TIMI flow and MBG. Of all angiographic, electrocardiographic, and CMR variables, LGE infarct size was the strongest predictor for baseline LV function and volumes. However, presence of LGE MVO was the strongest parameter to predict change at followup. Regional analysis showed that only $6 \%$ (23/372) of dysfunctional segments with MVO completely recovered during follow-up, compared to 35\% (631/1.786) without MVO (odds ratio $0.18, \mathrm{p}<0.0001$ ). MVO was associated with wall thinning and less improvement of wall thickening, independent of infarct transmurality.

\section{Conclusion}

LGE MVO is a better prognostic marker than other currently used determinants of microvascular injury, and predicts global and regional functional recovery in patients after reperfused AMI, beyond infarct transmurality. 


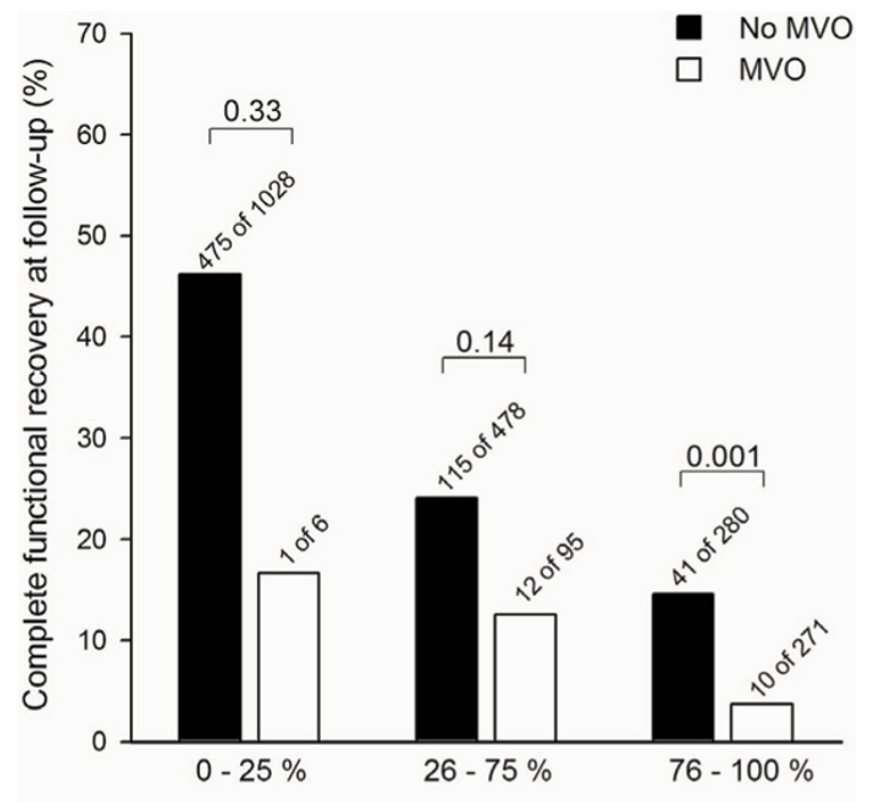

Segmental extent of late gadolinium enhancement

\section{Figure I}

LGE MVO is a better prognostic marker than other currently used determinants of microvascular injury. LGE MVO predicts global and regional functional recovery in patients after reperfused $\mathrm{AMI}$, beyond infarct transmurality.

Publish with Bio Med Central and every scientist can read your work free of charge

"BioMed Central will be the most significant development for disseminating the results of biomedical research in our lifetime. "

Sir Paul Nurse, Cancer Research UK

Your research papers will be:

- available free of charge to the entire biomedical community

- peer reviewed and published immediately upon acceptance

- cited in PubMed and archived on PubMed Central

- yours - you keep the copyright 